\title{
A highly enantioselective abiotic receptor for malate dianion in aqueous solution $\uparrow+$
}

\author{
Almudena González-Álvarez, ${ }^{a}$ Ignacio Alfonso, ${ }^{* b}$ Pilar Díaz, $^{c}$ Enrique García-España ${ }^{c}$ and Vicente Gotor*a \\ Received (in Austin, TX, USA) 15th December 2005, Accepted 17th January 2006 \\ First published as an Advance Article on the web 3rd February 2006 \\ DOI: 10.1039/b517729d
}

The highly enantioselective molecular recognition of the malate dianion by a synthetic receptor in aqueous solution has been studied by potentiometric titrations, mass spectrometry (ESIMS), diffusion measurements (PGSE NMR) and molecular modeling.

The molecular recognition of biologically important anions by simple synthetic receptors is an emerging topic in the field of supramolecular chemistry. ${ }^{1}$ Among others, malate dicarboxylate (1), shown in Scheme 1, presents interesting features which make it a formidable target molecule. First of all, it is an essential metabolic intermediate, the abnormal levels of its concentration being closely related to some disorders and diseases. ${ }^{2}$ From the chemical point of view, its highly negative charge density at physiological conditions and the presence of an additional H-bonding hydroxyl group make its molecular recognition in aqueous solution especially challenging. Besides, this molecule is chiral, only one of its enantiomers being present in most of its biological functions. Accordingly, there are some enzymatic<smiles>O=C(O)CC(O)C(=O)[O-]</smiles>

$(S)-1$<smiles>O=C([O-])CC(O)C(=O)O</smiles>

$(R)-1$<smiles>C[C@H]1[CH]CCC[C@H]1NCc1cccc(CN[C@@H]2CCCC[C@H]2NCc2cccc(CN[C@H]3CCCC[C@H]3C)n2)n1</smiles>

$(R, R)-2$
Scheme 1 Chemical structures of substrates $(R / S)-1$ and receptor $(R, R)-2$.

${ }^{a}$ Departamento de Químca Orgánica e Inorgánica, Universidad de Oviedo, Julián Clavería,33071, Oviedo,Spain.E-mail:vgs@fq.uniovi.es ${ }^{b}$ Departamento de Química Inorgánica y Orgánica, ESTCE,

Universidad Jaume I, Avd. Sos Bainat s/n, E-12080, Castellón, Spain. E-mail:ialfonso@qio.uji.es

'Instituto de Ciencia Molecular, Departamento de Químca Inorgánica y Orgánica, Universidad de Valencia, Cl Dr. Moliner, 50, E-46100,

Burjassot, Valencia, Spain

$\uparrow$ Electronic supplementary information (ESI) available: Experimental and computational details, tables of potentiometric titration data and plots of the species distributions, selected ESI mass spectra, PGSE NMR details, and Cartesian coordinates for the geometries of optimized structures. See DOI: $10.1039 / \mathrm{b} 517729 \mathrm{~d}$

* Dedicated to Professor Victor Riera on the occasion of his 70th birthday. receptors in nature able to bind and transform the malate dianion, with a high degree of chemo- and enantioselectivity. ${ }^{3}$ Thus, there are differences of biological activity depending on the absolute configuration of the chiral center of $\mathbf{1}$. Related to that, some efforts have been developed recently to distinguish between malate enantiomers in order to detect fraud in the food industry. ${ }^{4}$

Following the studies on molecular recognition of chiral biologically interesting dicarboxylates, ${ }^{5}$ we decided to test receptor $(R, R)$-2 (Scheme 1) for the binding of 1 in aqueous solution. ${ }^{6}$ Based on our previous experience ${ }^{5 d f}$ and considering the molecular structure, acid-base properties ${ }^{7}$ and the $D_{2}$ chiral symmetry of $(R, R)-\mathbf{2}$, we envisioned this abiotic receptor as a good candidate for enantioselective binding of malate enantiomers. The values of the binding constants between $(R, R)-2$ and both enantiomers of $\mathbf{1}$, obtained by potentiometric titrations, are shown in Table $1 .^{7}$ Values of enantioselectivity defined as the ratio of stability constants $\left(K_{S} / K_{R}\right)$ and the difference of the free energy of the diasteromeric complexes $(\Delta \Delta G)$ are also given for comparison. Due to the existence of overlapping equilibria, a clearer representation of conditional stability constants ${ }^{8}\left(\log K_{\text {cond }}\right)$ is shown in Fig. 1. The receptor forms strong $1: 1$ supramolecular complexes with both enantiomers of $\mathbf{1}$ throughout the whole $\mathrm{pH}$

Table $1 \log K$ values for the formation of the complexes between $(R, R)-\mathbf{2}(\mathrm{L})$ and $(R / S)-\mathbf{1}(\mathrm{A})(0.15 \mathrm{M} \mathrm{NaCl}, 298 \mathrm{~K})$

\begin{tabular}{lcrrl}
\hline Reaction $^{a}$ & $\begin{array}{l}\log K \\
(R)-1\end{array}$ & \multicolumn{1}{l}{$\begin{array}{l}\log K \\
(S)-1\end{array}$} & $K_{S} / K_{R}$ & $\Delta \Delta G / \mathrm{kJ} \mathrm{mol}^{-1}$ \\
\hline $\mathrm{L}+\mathrm{A}=\mathrm{LA}$ & $4.40(2)^{b}$ & $5.47(3)$ & 11.75 & 6.12 \\
$\mathrm{~L}+\mathrm{H}+\mathrm{A}=\mathrm{LHA}$ & $13.41(2)$ & $14.37(3)$ & 9.12 & 5.45 \\
$\mathrm{~L}+2 \mathrm{H}+\mathrm{A}=\mathrm{LH}_{2} \mathrm{~A}$ & $21.74(1)$ & $22.57(2)$ & 6.76 & 4.75 \\
$\mathrm{~L}+3 \mathrm{H}+\mathrm{A}=\mathrm{LH}_{3} \mathrm{~A}$ & $26.52(2)$ & $27.22(3)$ & 5.01 & 4.00 \\
$\mathrm{~L}+4 \mathrm{H}+\mathrm{A}=\mathrm{LH}_{4} \mathrm{~A}$ & $30.59(2)$ & $31.28(3)$ & 4.90 & 3.96 \\
$\mathrm{~L}+5 \mathrm{H}+\mathrm{A}=\mathrm{LH}_{5} \mathrm{~A}$ & $33.62(5)$ & $34.19(7)$ & 3.72 & 3.25 \\
${ }^{a}$ Charges omitted for clarity. ${ }^{b}$ Values in parentheses correspond to \\
the standard deviation in the last significant figure. \\
\hline
\end{tabular}

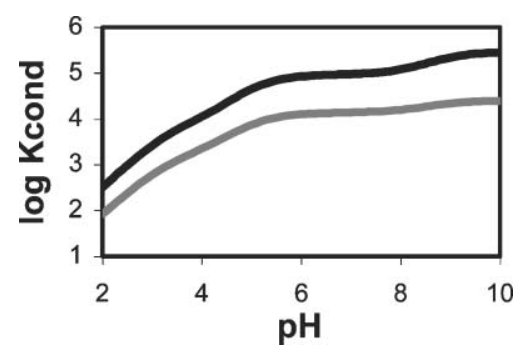

Fig. 1 Plots of $\log K_{\text {cond }} v$ s. $\mathrm{pH}$ for (R)-1 (grey) and (S)-1 (black). 
range studied, ruling out electrostatic attraction as the only driving force for the process. Other factors such as H-bonding, dipoledipole or solvophobic interactions could play an essential role in this case. Regarding the enantioselectivity of the receptor, $(R, R)-2$ forms more stable complexes with $(S)$-1 than with the $(R)$ enantiomer $\left(K_{S}>K_{R}\right)$. This selectivity is of the same sign over the $\mathrm{pH}$ range tested, being very high at basic $\mathrm{pH}$ (at $\mathrm{pH}=10, K_{S} / K_{R}=$ 11.50) but lower when the $\mathrm{pH}$ was decreased (at $\mathrm{pH}=2, K_{S} / K_{R}=$ 3.89). Interestingly, at neutral $\mathrm{pH}$, where the uncharged diprotonated supramolecular complex $\left[\mathrm{LH}_{2} \mathrm{~A}\right]$ predominates, ${ }^{7}$ the interaction is also highly enantioselective (at $\mathrm{pH}=6.5$, $K_{S} / K_{R}=6.76$ ).

As an alternative technique, electrospray ionization mass spectrometry (ESI-MS) has been recently used to study the formation of diastereomeric complexes with chiral selectors, showing a good correlation with the enantiodiscrimination found in solution. ${ }^{9}$ Thus, the ESI-MS spectrum of a solution of $(R, R)-2$ and $(S)-1(1: 1$ mixture, $\mathrm{pH}=6.4)$ showed peaks corresponding to the species $\left[\mathrm{LAH}_{3}\right]^{+}(\mathrm{m} / \mathrm{z}=569)$ and $\left[\mathrm{LAH}_{4}\right]^{2+}(\mathrm{m} / \mathrm{z}=285)$, where $\mathrm{L}$ and $\mathrm{A}$ represent $(R, R)-\mathbf{2}$ and $(S)-\mathbf{1}$, respectively. Both full isotopic pattern analysis and tandem MS/MS experiments supported the assignation of the peaks (ESI $\dagger$ ). However, when the ESI-MS was acquired with $(R)-\mathbf{1}$ in exactly the same experimental and operational conditions, the peaks corresponding to the supramolecular species were lacking. These experimental evidences strongly support the higher stability of the supramolecular complex with the $(S)$-enantiomer, and nicely correlate with the potentiometric measurements.

We also tried to get a three dimensional picture of the complexes with the help of molecular modeling. ${ }^{10}$ The obtained minimized structures for the diastereomeric complexes formed between diprotonated $(R, R)-\mathbf{2}$ and the malate dianion are shown in Fig. 2. The receptor shows a $D_{2}$ symmetrical helical conformation with the six nitrogen atoms on the vertices of an octahedron. The protonation takes place at alternate secondary nitrogen atoms and the structure is stabilized by several intramolecular hydrogen bonds. ${ }^{6 b}$ Malate dianion, in a gauche conformation, fits within the grove formed by the macrocyclic structure and its carboxylates bind to both ammonium groups of the receptor, showing a good
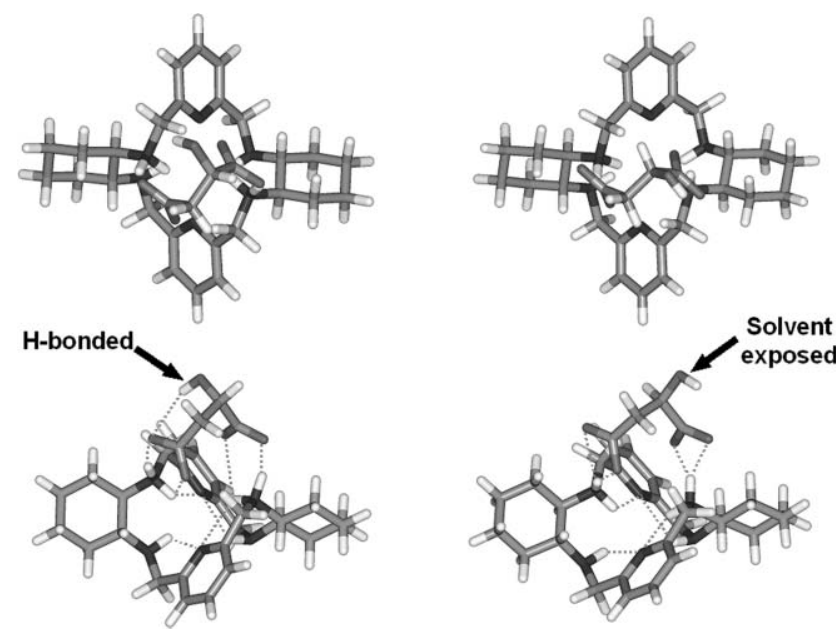

Fig. 2 Front (up) and side (down) views of the optimized geometries for the complexes formed between $(R, R)-\mathbf{2}$ and $(S)-\mathbf{1}$ (left) or $(R)-\mathbf{1}$ (right). geometrical complementarity. Key differences can be found by comparing both diastereomeric complexes. First of all, the receptor showed a slightly larger distortion from the ideal $D_{2}$ symmetry upon binding to $(R)-1{ }^{10}$ Besides, the relative disposition between the macrocycle and dianion forces the $\mathrm{OH}$ of the chiral center to point towards the receptor, intramolecularly H-bound to the $\beta$-carboxylate group of $(S)-\mathbf{1}$ (distance $\mathrm{OH} \cdots \mathrm{OOC}=2.514 \AA$ ), while being solvent exposed for $(R)-\mathbf{1}$ (Fig. 2). These two factors would account for a higher stability of the complex with $(S)-\mathbf{1}$. Accordingly, the computed energy difference ${ }^{10}$ was $6.5 \mathrm{~kJ} \mathrm{~mol}^{-1}$ favorable to the formation of the complex with $(S)-\mathbf{1}$, in reasonable agreement with the reported experimental data. Besides, this model also reflects the higher enantioselectivity observed at basic $\mathrm{pH}$. Computed geometries of $[\mathrm{LA}]^{2-}$ species rendered a larger energy difference for the diastereomeric complexes $\left(\Delta E=15.7 \mathrm{~kJ} \mathrm{~mol}^{-1}\right)$ in a good correlation with experimental data. Concomitantly, the intramolecular $\mathrm{OH}^{\cdots}$ OOC distance for the $(S)$-1 diastereomeric complex becomes shorter $(2.375 \AA)$, suggesting a more efficient stabilizing effect of the $\mathrm{OH}$ group at higher $\mathrm{pH}$. On the other hand, the importance of the $\mathrm{OH}$ group in the enantioselectivity is also supported by the very low stereoselectivity of $(R, R)-\mathbf{2}$ in the binding of methylsuccinic dianion enantiomers. ${ }^{11}$

Additional information about the structures of the supramolecular species was obtained by NMR experiments. Analyses of ${ }^{1} \mathrm{H}$, ${ }^{13} \mathrm{C}$ and ${ }^{15} \mathrm{~N}$ NMR spectra of a $1: 1$ solution mixture of $(R, R)-2$ and either $(R)$ or $(S)-\mathbf{1}\left(\mathrm{D}_{2} \mathrm{O}, 303 \mathrm{~K}, \mathrm{pD}=6.5\right)$ revealed that the receptor shows an effective $D_{2}$ symmetry in solution. This implies a fast complexation-decomplexation equilibrium on the NMR timescale. Unfortunately, there were no significant chemical shift differences between diastereomeric complexes or unambiguous intermolecular NOEs which could give us additional structural information. Nevertheless, definitive proofs for the solution behavior of both diastereomeric complexes were obtained by pulse gradient spin echo (PGSE) measurements. ${ }^{12}$ By the accurate measurement of the dependence of NMR signal intensities on gradient strength (Fig. 3), some hydrodynamic parameters can be extracted (Table 2). As the complexation-decomplexation equilibrium would change the size of the species in solution, the observed self-diffusion rate $(D)^{13}$ of a given signal would be the time average of those of the interconverting species causing that signal. Thus, the smaller the $D$ value, the larger the size (hydrodynamic radius, $\left.r_{\mathrm{H}}\right)^{14}$ of the effective diffusing species and, thus, more stable and with longer existence would be the

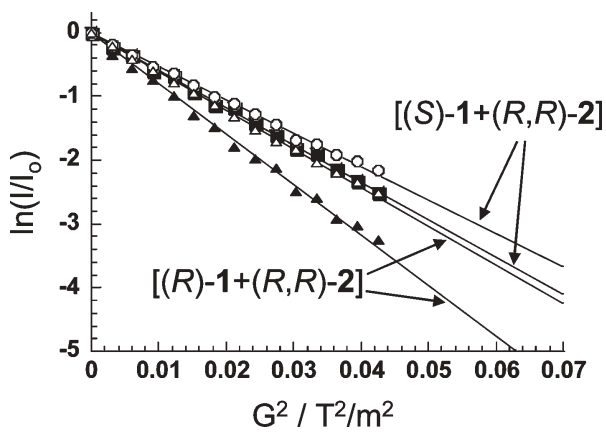

Fig. 3 Plots of $\ln \left(I / I_{\mathrm{o}}\right) v s . G^{2}$ for samples containing $[(S)-\mathbf{1}+(R, R)-2]$ or $[(R)-\mathbf{1}+(R, R)-2]\left(10 \mathrm{mM}, 500 \mathrm{MHz}, \mathrm{D}_{2} \mathrm{O}, \mathrm{pD}=6.5,303 \mathrm{~K}\right)$. Open symbols correspond to signal $H_{\mathrm{eq} \beta}$ from the receptor and solid symbols to signal $\mathrm{C} 3 H$ from the substrate (see Scheme 1 for atom labeling). 
Table 2 Hydrodynamic parameters of the samples containing $1: 1$ mixtures of $(R, R)-\mathbf{2}$ and $(R / S)-\mathbf{1}\left(10 \mathrm{mM}\right.$ each, $500 \mathrm{MHz}, \mathrm{D}_{2} \mathrm{O}, \mathrm{pD}=$ $6.5,303 \mathrm{~K})$

\begin{tabular}{|c|c|c|c|c|}
\hline Entry & Sample & Signal & $D / 10^{-10} \mathrm{~m}^{2} \mathrm{~s}^{-1}$ & $r_{\mathrm{H}} / \AA^{a}$ \\
\hline 1 & $(R, R)-\mathbf{2}+(S)-\mathbf{1}$ & $\mathrm{C} 3 H(\mathbf{1})$ & $5.80( \pm 0.08)$ & 3.9 \\
\hline 2 & $(R, R)-\mathbf{2}+(S)-\mathbf{1}$ & $H_{\mathrm{eq} \beta}(2)$ & $5.13( \pm 0.06)$ & 4.4 \\
\hline 3 & $(R, R)-2+(R)-1$ & $\mathrm{C} 3 H$ (1) & $7.65( \pm 0.11)$ & 3.0 \\
\hline 4 & $(R, R)-2+(R)-1$ & $H_{\mathrm{eq} \beta}(2)$ & $5.95( \pm 0.05)$ & 3.8 \\
\hline 5 & Calculated $^{b}$ & - & $4.38^{a, b}$ & $5.2^{b}$ \\
\hline
\end{tabular}

supramolecular structure. When we compare the self-diffusion rates measured using one diastereotopic proton at position $\mathrm{C} 3$ of 1 (entries 1 and 3 in Table 2), we observed that, under the same experimental conditions, the sample containing $(R)-\mathbf{1}$ seems to diffuse faster than the one containing $(S)$-1. This effect can be easily seen by the larger negative slope displayed in Fig. 3. More impressively, this trend was also observed by comparing signals of the receptor in both samples (entries 2 and 4), although the difference is smaller due to a more similar size of free and complexed receptor. Finally, for the sample containing $(S)-\mathbf{1}$, the measured $D$ values using either receptor or substrate signals (entries 1 and 2) are closer to each other than those measured in the sample with $(R)-\mathbf{1}$ (entries 3 and 4). This implies that $(S)-\mathbf{1}$ diffuses in higher proportion within the receptor than $(R)-\mathbf{1}$, in good correlation with the enantioselectivity observed using other techniques. To the best of our knowledge, this is the first time that PGSE techniques have been used to study supramolecular anion complexes with polyazamacrocycles in aqueous solution.

In summary, our combination of techniques strongly supports a highly enantioselective molecular recognition process which is, as far as we know, the best displayed by a synthetic receptor towards malate enantiomers at physiological conditions. We are currently studying the interaction between $(R, R)-\mathbf{2}$ and other chiral dicarboxylates in order to refine our model of binding and to design more efficient and selective related receptors.

Financial support from the Spanish Ministerio de Educación y Ciencia (BQU2003-09215-CO1, CTQ-2004-04185) is gratefully acknowledged. We also thank personal support for A.G.-A. (III PRI, Principado de Asturias), P.D. (Juan de la Cierva program, M.E.C.) and I.A. (Ramon y Cajal program, M.E.C.).

\section{Notes and references}

1 A. Bianchi, K. Bowman-James and E. García-España, Supramolecular Chemistry of Anions, VCH, Weinheim, 1997.

2 (a) A. S-Y. Lo, C.-T. Liew, S.-M. Ngai, S. K.-W. Tsui, K.-P. Fung, C.-Y. Lee and M. M.-Y. Waye, J. Cell. Biochem., 2005, 94, 763; (b) P. Bubber, V. Haroutunian, G. Fisch, J. P. Blass and G. E. Gibson,
Ann. Neurol., 2005, 57, 695; (c) B. A. Barshop, Mitochondrion, 2004, 4, 521.

3 (a) M. Bandell and J. Lolkema, Biochemistry, 2000, 39, 13059; (b) M. Bandell and J. Lolkema, Biochemistry, 1999, 38, 10352.

4 T. Tsukatani and K. Matsumoto, Talanta, 2005, 65, 396

5 (a) I. Stibor and P. Zlatuskova, Top. Curr. Chem., 2005, 255, 31; (b) A. Ragusa, S. Rossi, J. M. Hayes, M. Stein and J. K. Kilburn, Chem.Eur. J., 2005, 11, 5674; (c) A. M. Piatek, Y. J. Bomble, S. L. Wiskur and E. V. Anslyn, J. Am. Chem. Soc., 2004, 126, 6072; (d) C. Miranda, F. Escartí, L. Lamarque, M. J. Yunta, P. Navarro, E. García-España and M.-L. Jimeno, J. Am. Chem. Soc., 2004, 126, 823; (e) I. Alfonso, B. Dietrich, F. Rebolledo, V. Gotor and J.-M. Lehn, Helv. Chim. Acta, 2001, 84, 280; (f) I. Alfonso, F. Rebolledo and V. Gotor, Chem.-Eur. J., 2000, 6, 3331; (g) J. J. Lavigne and E. V. Anslyn, Angew. Chem., Int. $E d$. 1999, 38, 3666; (h) J. L. Sessler, A. Andrievsky, V. Král and V. Lynch, J. Am. Chem. Soc., 1997, 119, 9385.

6 For the synthesis of $(R, R)$-2 see: (a) A. González-Álvarez, I. Alfonso, F. López-Ortiz, A. Aguirre, S. García-Granda and V. Gotor, Eur. J. Org. Chem., 2004, 1117; (b) P. M. Fitzsimmons and S. C. Jackels, Inorg. Chim. Acta, 1996, 246, 301.

7 Potentiometric titrations were carried out using a reaction vessel waterthermostatted at $25.0 \pm 0.1{ }^{\circ} \mathrm{C}$ in an argon atmosphere. As it is present in biological systems in similar concentrations, $0.15 \mathrm{~mol} \mathrm{dm}^{-3} \mathrm{NaCl}$ was used as supporting electrolyte. The HYPERQUAD program (P. Gans, A. Sabatini and A. Vacca, Talanta, 1996, 43, 1739) was used to process the data and calculate both the protonation and stability constants for those not given in the Table 1, see ESI + .

8 M. T. Albelda, M. A. Bernardo, E. García-España, M. L. RodinoSalido, S. V. Luis, M. J. Melo, F. Pina and C. Soriano, J. Chem. Soc., Perkin Trans. 2, 1999, 2545.

9 (a) A. Flippi, F. Gasparrini, M. Pierini, M. Speranza and C. Villani, J. Am. Chem. Soc., 2005, 127, 11912; (b) K. Schug, P. Fryčák, N. M. Maier and W. Lindner, Anal. Chem., 2005, 77, 3660.

10 Theoretical calculations were performed with Spartan 04 program. Initial Monte Carlo conformational searches with MMFFaq force field minimization were performed to locate the global minima for every diastereomeric complex. The structures thus obtained were fully minimized at the PM3 semiempirical quantum level of theory. Frequency analyses showed they are true minima of energy. Finally, for a more accurate value of energy, a single point energy calculation was carried out for every structure, using the mixed QM/MM method available in Spartan 04, which considers implicit water molecules around the solute. The energy of the solute was computed at the ab initio HF/6$31 \mathrm{G}^{*}$ level of theory. For further details also see ESI†.

11 Potentiometric measurements of complexes formed by $(R, R)-\mathbf{1}$ and $(R /$ $S)$-methylsuccinic acid yielded values of $K_{S} / K_{R}<1.6$.

12 (a) P. S. Pregosin, P. G. A. Kumar and I. Fernández, Chem. Rev., 2005, 105, 2977; (b) E. Martínez-Vivente, P. S. Pregosin, L. Vial, C. Herse and J. Lacour, Chem.-Eur. J., 2004, 10, 2912.

13 For the accurate measurement of self diffusion coefficients $(D)$, the value of the HDO signal in deuterium oxide at $303 \mathrm{~K}\left(D_{\mathrm{HDO}}=1.9 \times\right.$ $10^{-9} \mathrm{~m}^{2} \mathrm{~s}^{-1}$ ) was used as an internal standard for every sample. Although $D$ values are dependent on solvent, temperature and concentration of the sample, as the measurements were performed under the same experimental conditions for samples containing either $(R)-\mathbf{1}$ or $(S)-\mathbf{1}$, a direct comparison should be suitable to extract conclusions. For more details, see ESI $\uparrow$.

14 The hydrodynamic radius $\left(r_{\mathrm{H}}\right)$ values were estimated approximating the shape of the molecule to a sphere and using the Stokes-Einstein equation: $D=k_{\mathrm{B}} T / 6 \pi \eta r_{\mathrm{H}}$ where $k_{\mathrm{B}}$ is the Boltzmann constant and $\eta$ is the viscosity of deuterated water at $303 \mathrm{~K}\left(0.976 \times 10^{-3} \mathrm{~kg} \mathrm{~m}^{2} \mathrm{~s}^{-2}\right)$. For more details, see ESI†. 